\title{
Native and non-native sources of carbohydrate correlate with abundance of an invasive ant
}

\author{
Lori Lach ${ }^{1,2}$, Benjamin D. Hoffmann ${ }^{3}$, Melinda L. Moir ${ }^{2,4}$ \\ I College of Science and Engineering, James Cook University, PO Box 6811 Cairns, Queensland 4870, Aus- \\ tralia 2 School of Biological Sciences, The University of Western Australia, 35 Stirling Hwy, Crawley, WA 6009, \\ Australia 3 CSIRO, Tropical Ecosystems Research Centre, PMB 44, Winnellie, NT, 0822, Australia 4 Depart- \\ ment of Primary Industries and Regional Development, Diagnostic Laboratory Services, 3 Baron-Hay Court, \\ South Perth, WA 6151, Australia \\ Corresponding author: Lori Lach (lori.lach@jcu.edu.au)
}

Academic editor:D. Pureswaran | Received 24 August 2020 | Accepted 1 December 2020 | Published 17 December 2020

Citation: Lach L, Hoffmann BD, Moir ML (2020) Native and non-native sources of carbohydrate correlate with abundance of an invasive ant. NeoBiota 63: 155-175. https://doi.org/10.3897/neobiota.63.57925

\begin{abstract}
Invasive species threaten many ecological communities and predicting which communities and sites are invasible remains a key goal of invasion ecology. Although invasive ants often reach high abundances in association with plant-based carbohydrate resources, the source and provenance of these resources are rarely investigated. We characterized carbohydrate resources across ten sites with a range of yellow crazy ant abundance in Arnhem Land, Australia and New Caledonia to determine whether yellow crazy ant (Anoplolepis gracilipes) abundance and trophic position correlate with carbohydrate availability, as well as the relative importance of native and non-native sources of carbohydrates to ant diet. In both locations, measures of yellow crazy ant abundance strongly positively correlated with carbohydrate availability, particularly honeydew production, the number of tended hemipterans, and the number of plants with tended hemipterans. In Arnhem Land, 99.6\% of honeydew came from native species, whereas in New Caledonia, only $0.2 \%$ of honeydew was produced by a native hemipteran. More honeydew was available in Australia due to three common large-bodied species of Auchenorrhyncha honeydew producers (treehoppers and leafhoppers). Yellow crazy ant trophic position declined with increasing yellow crazy ant abundance indicating that in greater densities the ants are obtaining more of their diet from plant-derived resources, including honeydew and extrafloral nectar. The relationships between yellow crazy ant abundance and carbohydrate availability could not be explained by any of the key environmental variables we measured at our study sites. Our results demonstrate that the positive correlation between yellow crazy ant abundance and honeydew production is not contingent upon the provenance of the hemipterans. Native sources of carbohydrate may play an underappreciated role in greatly increasing community invasibility by ants.
\end{abstract}

Copyright Lori Lach et al. This is an open access article distributed under the terms of the Creative Commons Attribution License (CC BY 4.0), which permits unrestricted use, distribution, and reproduction in any medium, provided the original author and source are credited. 


\section{Keywords}

Anoplolepis gracilipes, extrafloral nectar, Hemiptera-ant mutualisms, honeydew, invasion ecology, stable isotopes, trophic position

\section{Introduction}

Many hypotheses to explain invasion success focus primarily on the traits of introduced species while fewer consider the characteristics of the recipient community (Catford et al. 2009). Invasion syndromes have been proposed as a means of advancing invasion science by considering both species traits and ecosystem characteristics as a means to predict invasions in different contexts (Kueffer et al. 2013; Perkins and Nowak 2013; Novoa et al. 2020). Despite the realization that recipient community characteristics influence the outcomes of species introductions, including whether introduced species become invasive, studies that investigate properties of invaded communities, or their invasibility, are fewer and declining compared to studies that focus on invader traits, or their invasiveness (Godoy 2019).

Invasibility and invasiveness are defined at least in part by the availability of resources in a community and the ability of the introduced species to acquire them, respectively. Introduced species that are able to acquire resources either by outcompeting native species, filling empty niches, or capitalizing on resource pulses are more likely to be invasive (Gonzalez et al. 2010; Li and Stevens 2012). Some of these resources are acquired via interactions with resident species. For example, introduced honey bees require pollen and nectar from resident plants in order to establish and spread, and at least a third of invasive woody species benefit from resident mycorrhizae (Traveset and Richardson 2014). Where one or more non-native species provide resources that facilitate invasion, the phenomenon is often termed 'invasional meltdown' (Simberloff and Von Holle 1999). Interactions in which native species provide resources are perhaps less appreciated, but not necessarily less important (Northfield et al. 2018).

Invasive ants are highly competitive and often reach high abundances in association with availability of plant-based carbohydrate resources (Holway et al. 2002; Lach 2003). High abundance of invasive ants has been associated with the monopolization of carbohydrate-rich resources in a range of species and geographic locations (Helms 2013) including yellow crazy ants (Anoplolepis gracilipes (Smith)) on Christmas Island (O'Dowd et al. 2003) and Samoa (Savage et al. 2011); Argentine ants (Linepithema humile (Mayr) in the US (Rowles and Silverman 2009); red imported fire ants (Solenopsis invicta Buren) in the US (Helms and Vinson 2002; Wilder et al. 2011b), big-headed ants (Pheidole megacephala (F.)) in the Seychelles (Gaigher et al. 2011); and whitefooted ants (Technomyrmex albipes (Smith)) in Mauritius (Lach et al. 2010). Thus, observations of invasive ant monopolization of sugary-resources are common across multiple locations and taxa.

Nonetheless, several gaps in our knowledge of the relationship between carbohydrate availability and ant invasions remain, such as the effects of ant abundance and the source and provenance of the carbohydrate resource. We have little knowledge of 
whether access to carbohydrate resources is linked to invasive ant abundance when invasive ant abundance is low or populations are just establishing (Helms 2013). Evidence from laboratory experiments suggest that access to carbohydrates is fundamental to colony growth and activity (e.g., Grover et al. 2007; Wilder et al. 2011a; Wittman et al. 2018; Lach et al. 2019). If invasive ant abundance is low, the ants may not be able to outcompete other resident ant species to gain access to resources (sensu Drescher et al. 2011). The invaders may then require some minimum threshold of carbohydrate availability above which their populations can increase. Such a threshold could explain lag time i.e., the delay between the establishment of an introduced ant and when it becomes dominant. The extent to which the source of the carbohydrate is important also deserves more investigation. Honeydew from non-native hemipterans is often associated with large invasive ant populations (Helms 2013). However, the quantity and quality of honeydew and whether the hemipterans are native or introduced are rarely reported and may also characterize the invasibility of a site (Hoffmann and Kay 2009; Helms 2013). Whether nectar availability influences invasibility is also an open question. Floral nectar, which is thought to be protected from the thieving activity of ants generally (Junker et al. 2011), is frequently visited by invasive ants in some systems (Blancafort and Gómez 2005; Lach 2013; LeVan et al. 2014). Extrafloral nectar also often attracts a range of ant species, including invasive ants (Savage and Rudgers 2013; Ludka et al. 2015). In addition to potentially facilitating high abundances of invasive ants, carbohydrate resources can provide the mechanism by which invasive ants are able to effect changes to their recipient community via competitive interactions or mutualisms (Lach 2003). Therefore, further understanding the relevance of both the source and provenance of carbohydrate-rich resources at different invasive ant densities may provide insights into site invasibility and ant invasiveness.

The yellow crazy ant is among the world's most damaging invasive ant species, and is most well-known for the cascade of dramatic ecosystem-level changes on Christmas Island (O'Dowd et al. 2003). The density of foraging yellow crazy ants on Christmas Island is reportedly among the highest ever recorded for any ant species in the world (2254 workers $/ \mathrm{m}^{2}$, Abbott 2005). Prior to arrival of the lac scale insect (Tachardina aurantica (Cockerell, 1903), the ant had been present on the island at low densities for approximately 70 years with little observable ecological consequence (O'Dowd et al. 2003). Its abundance elsewhere in its introduced range varies greatly in space and time, with some populations persisting at relatively low density, some achieving extraordinarily high densities, and some crashing due to unknown causes (Lester and Tavite 2004; Lach et al. 2010; Gruber et al. 2013; Cooling and Hoffmann 2015; Lach et al. 2016). Though the ant is widely reported to consume a variety of carbohydrate resources (honeydew: Hill et al. 2003; O'Dowd et al. 2003; Lach et al. 2010; floral nectar: Lach 2005; Sinu et al. 2017; extrafloral nectar: Lach and Hoffmann 2011; Savage and Rudgers 2013; Hoffmann et al. 2014), the extent to which the fate of its introduced populations is tied to the availability of carbohydrate resources is unclear. Yellow crazy ant invasions are predominantly known from tropical islands (Janicki et al. 2016; Guénard et al. 2017), which often have an assemblage of cosmopolitan honeydew-producing insects, thus limiting the opportunity to disentangle potential 
factors affecting invasiveness and invasibility. In Samoa, artificially increasing sucrose availability on an extrafloral nectary plant increased yellow crazy ant activity on the plant but also decreased the ant's tending of honeydew-producing insects (Savage et al. 2011), possibly indicating a limit to which yellow crazy ants can respond to carbohydrate availability.

We aimed to further elucidate the relationship between carbohydrate origin and ant invasions. We chose the yellow crazy ant as our study organism because it is globally widespread, obtains carbohydrates from a large variety of resources, and the outcomes of its introductions are variable. We assessed yellow crazy ant abundance and trophic position and availability of carbohydrate-rich resources across sites in a continental and an island ecosystem to determine 1) whether yellow crazy ant abundance positively correlates with carbohydrate availability across a range of yellow crazy ant densities; 2) the relative importance of native and non-native sources of carbohydrate; and 3) whether consumption of carbohydrate by yellow crazy ants increases with its availability as evidenced by declining trophic position. We acknowledge that correlation does not demonstrate causation, and that even if yellow crazy ant abundance and carbohydrate availability correlate, they may be non-interactive and driven by responses to the environment. To test this possibility we also measured several other key habitat characteristics and investigated their relationships with carbohydrate availability and yellow crazy ant abundance.

\section{Materials and methods}

\section{Sites}

We conducted the study in savannah woodlands of northeast Arnhem Land in Australia's Northern Territory and in maquis shrubland in New Caledonia. Both of these habitats support a range of yellow crazy ant densities and have accessible vegetation amenable to finding and capturing honeydew-producing insects. Temperatures in Arnhem Land, range from $22.4-30.6{ }^{\circ} \mathrm{C}$ with average annual rainfall of $1456 \mathrm{~mm}$ (Australian Bureau of Meteorology). Temperatures in New Caledonia, range from $17.3-29.7^{\circ} \mathrm{C}$ with average annual rainfall of $1070 \mathrm{~mm}$ (Meteo France). In each location, we selected five $20 \mathrm{~m} \times 20 \mathrm{~m}$ sites with similar vegetation that were occupied by yellow crazy ants (Fig. 1). The five sites in each location (Suppl. material 1: Table S1) were separated by areas with vegetation different from the sites or expanses without yellow crazy ants and were a minimum of $500 \mathrm{~m}$ apart. Within each site, we positioned nine $1 \mathrm{~m}$-diameter sample plots $10 \mathrm{~m}$ apart in a 3 row $\times 3$ column grid. Sites in Arnhem Land had an overstory of Eucalyptus tetradonta (height approximately $5 \mathrm{~m}$ ), a sparse shrub layer, and a dense leaf litter layer. Sites in New Caledonia were dominated by shrubs (maximum height $3 \mathrm{~m}$ ), with an understory of grasses, sedges, and sparse leaf litter. We conducted the field work in the early dry season in each country (April in New Caledonia and June 2012 in Arnhem Land). 


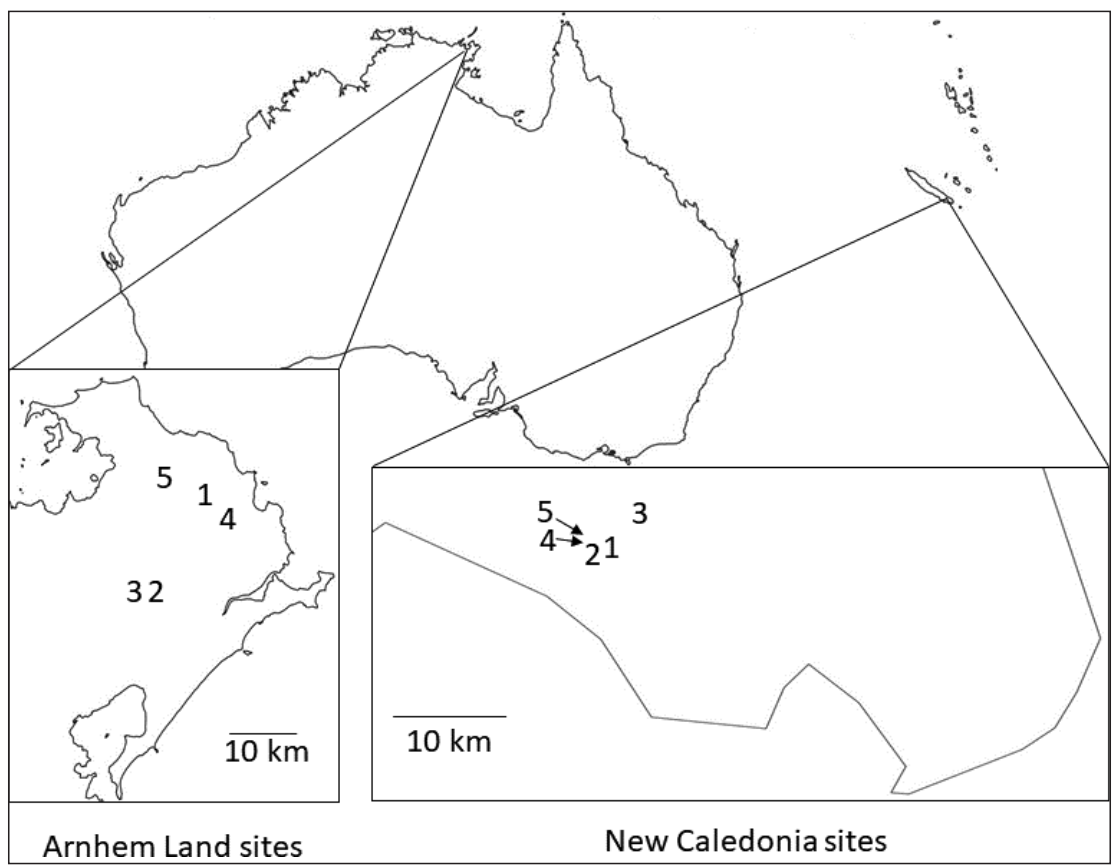

Figure I. Map of study sites in Arnhem Land, Australia and New Caledonia.

\section{Yellow crazy ant invasion history and abundance}

The yellow crazy ant's history in the two locations is poorly known. The yellow crazy ant was first recorded in Arnhem Land in 1990, but based on its distribution at that time, it is thought to have established itself several decades prior (Young et al. 2001). In New Caledonia, the ant has been present for at least a hundred years and is predominantly found in the maquis-shrubland (Berman et al. 2013). The yellow crazy ant's native range is unresolved (Wetterer 2005), but it is most widely distributed in southeast Asia and is considered to be invasive where it occurs in Australia and many islands and archipelagos throughout the Indo-Pacific (Janicki et al. 2016; Guénard et al. 2017). Its colonies have multiple queens and typically inhabit multiple interacting nests. The ant is $-4 \mathrm{~mm}$ in length, omnivorous, and displaces larger ant species (Hoffmann and Saul 2010).

Ant abundance is extremely difficult to measure directly. We therefore obtained four measures of relative yellow crazy ant abundance: card counts, abundance on two different kinds of lures (cat food and jam), and nest density. For card counts, at the center of each of the nine plots, we placed a $20 \mathrm{~cm} \times 20 \mathrm{~cm}$ laminated card with four equivalent-sized squares on the ground. We recorded the number of yellow crazy ants that walked over the square that was first touched for 30 seconds. After card counts, and in the same plots, we placed lures consisting of half teaspoons each of tuna cat food and jam spaced $10 \mathrm{~cm}$ apart. Lures were left for 30 minutes after which we counted and identified by sight ants at and within $1 \mathrm{~cm}$ of each lure. We totalled counts across 
the nine plots for card counts and each lure type. We conducted card counts and luring in early morning or late afternoon when temperatures were $22.5-25.5^{\circ} \mathrm{C}$. After characterizing the carbohydrate availability and habitat (see below), we measured nest density within a central $10 \mathrm{~m} \times 10 \mathrm{~m}$ plot within each site by placing cat food lures every $-2.5 \mathrm{~m}$ and following foraging workers to their nests. We considered a nest entrance within $40 \mathrm{~cm}$ of another entrance to be for the same nest (Hoffmann 2015). At the site with highest nest density (Arnhem Land 1), no recruitment trails were formed due to the extremely high ant abundance, and leaf litter was cleared by hand to expose the nest entrances.

\section{Carbohydrate availability}

To characterize carbohydrate availability, within each $1 \mathrm{~m}$ diameter plot we carefully scanned vegetation for hemipterans, flowers, and extrafloral nectaries. When plants had approximately $<100$ leaves within the plot, we examined all leaves and the parts of the stem that were within the plot for hemipterans. When plants shorter than $3 \mathrm{~m}$ had $>100$ leaves within the plot, we examined leaves on every second terminal branch within the plot. We conducted these surveys within 72 hours of card counts and luring. We recorded the number of hemipterans and fresh flowers and noted when they were being tended or occupied, respectively, and collected representative samples of tended hemipterans for identification. While examining the leaves, we also recorded the presence of extrafloral nectaries. We encountered extrafloral nectaries in Arnhem Land only, and with the exception of a single Passiflora vine, only on Acacia. We bagged representatives of each Acacia species for 24 hours and confirmed production of extrafloral nectar from these glands. The amount produced was too small to reliably measure in the field, so we used a number of extrafloral nectaries as a proxy for extrafloral nectar availability. Each Acacia phyllode had an extrafloral nectary, so we estimated the number of extrafloral nectaries in each plot to be the same as the number of Acacia phyllodes in the plot (Lach et al. 2020).

In Arnhem Land, our $1 \mathrm{~m}$ diameter plots occasionally included trees with canopies above $5 \mathrm{~m}$. To sample branches from large trees we lassoed a branch with a rope, pulled it on to a tarp, and examined the leaves and stems for hemipterans and flowers. Because the sampling was destructive, we limited the survey to trees that accounted for at least $10 \%$ of the canopy of a $1 \mathrm{~m}$ diameter plot and tree species for which the contribution to the canopy of the nine plots combined exceeded $10 \%$. Where possible, we sampled a branch over the plot, after estimating what fraction of its leaves were within the plot. Where it was not possible to sample the branch that extended over a plot, we sampled a branch from a nearby similarly sized tree of the same species with a more accessible branch.

We calculated honeydew production over 24 hours at each site using the standardized method of (Moir et al. 2018). We did this by weighing and identifying each specimen collected in the field to the lowest taxonomic rank possible. Using family identity and body mass (Method 1: Moir et al. 2018), we were able to calculate the estimated honeydew rate per individual. For Coccoidea species we used the power equation $y=$ 
$0.785 \times x^{0.672}$, for Psyllidae we used the null model $y=7.99$, for Aphididae we used the power equation $y=3.46 \times^{0.3156}$, and for both Cicadellidae and Membracidae we used the power model of Delphacidae $y=1.229 \times{ }^{0.7692}$ (table 2 in Moir et al. 2018). For the latter two families we did not use the exponential model of Cicadellidae from Moir et al. (2018) because the species in our study were phloem-, rather than xylem-, feeders and we would therefore not expect them to have the high levels of honeydew excretion as the larger-bodied xylem-feeders incorporated into the models of Moir et al. (2018). After calculating individual specimen honeydew production rates, we pooled the rates across all tended hemipterans for each site over 24 hours.

\section{Habitat characterization}

Within each $1 \mathrm{~m}$ diameter plot, we counted the number of stems, estimated leaf area, and characterized the ground cover, canopy cover, and vegetation complexity (Lach et al. 2020). To estimate total leaf area contributed by each plant for plants with fewer than 100 leaves, we counted all leaves; for plants with greater than 100 leaves, we counted a subset of leaves and multiplied by the reciprocal of the fraction the subset represented to achieve the total number of leaves that plant contributed to the plot. For leaves that were more or less ovate, we measured leaf length and width and approximated leaf area with the equation

$$
\text { Leaf area }=0.66256(1 \times \mathrm{w})^{1.01156}
$$

where 1 = leaf length and $\mathrm{w}=$ leaf width (Antunes et al. 2008). Few leaves were not generally ovate; for those we approximated area either as rectangles (e.g., for long thin Acacia phyllodes) or triangles (e.g., bracken). The objective was to apply a consistent method of leaf area estimation to allow comparison to other sites. Within each location, our sites had similar types of vegetation, therefore any errors in accuracy would be consistent and would not affect correlations with ant abundance. We summed the leaf area contributed by each plant to obtain a total leaf area per plot. We characterized ground cover by estimating percent ground cover of bare soil, leaf litter, rocks $(>1 \mathrm{~cm})$, grass, stems, and coarse woody debris ( $>2 \mathrm{~cm}$ diameter). We estimated canopy cover within each $1 \mathrm{~m}$ diameter plot at $10 \mathrm{~cm}$, and $>3 \mathrm{~m}$. To assess vegetation complexity, we placed a $2 \mathrm{~m}$ pole marked at $10 \mathrm{~cm}$ intervals in the middle of each $1 \mathrm{~m}$ plot and recorded the number of times plants touched the pole, the number of $10 \mathrm{~cm}$ size classes in which a plant touched the pole, and a height profile based on a weighted mean of height touches (Gibson et al. 1987) following the equation

$$
\sum_{i=1}^{N}\left(h_{i} x n_{i}\right) / \sum_{i=1}^{N}\left(n_{i}\right)
$$

where $h=$ the mid-point of height class $i, n=$ the number of touches at height class $i$, and $N=$ the number of height classes represented in the sample. We conducted the vegetation complexity assessment after all insect surveys to avoid disturbing insects. 


\section{Trophic position calculations}

We calculated the relative trophic position of yellow crazy ants at all sites with stable isotope analyses. We collected a minimum of four yellow crazy ant samples (consisting of 6-10 ants) per site, and a minimum of three hemipteran, spider, and plant samples per site, froze the arthropods at $-20{ }^{\circ} \mathrm{C}$ for $24 \mathrm{~h}$, and then oven dried all samples at $60^{\circ} \mathrm{C}$ for 24 hours. Yellow crazy ants were collected either before lure placement, or during lure placement from areas away from lures. We opportunistically collected hemipterans, spiders, and plants harbouring hemipterans within each $20 \mathrm{~m} \times 20 \mathrm{~m}$ site but only after ant and carbohydrate assessments. Prior to stable isotope analysis, we removed ant gasters to avoid biasing calculations with recently ingested material. A minimum of $0.6 \mathrm{mg}$ of each sample type was ground and weighed into tin capsules. Samples were analysed with a continuous flow system consisting of a Delta V Plus mass spectrometer connected with a Thermo Flush 1112 via Conflo IV (ThermoFinnigan, Germany) at the West Australian Biogeochemistry Centre at the University of Western Australia.

We calculated trophic position with a modification of Post (2002) as described in Lach et al. (2010). Briefly, we calculated the trophic position of each yellow crazy ant replicate by calculating the proportion of dietary inputs from first $(\rho 1)$ and second $(\rho 2)$ sources with the equations

$$
\begin{gathered}
\rho_{1}=\left[\delta^{15} \mathrm{~N}_{\text {yellow crazy ant }}-\delta^{15} \mathrm{~N}_{(2)}-\Delta_{\mathrm{N}^{\prime \prime}}\right] /\left\{\left[\delta^{15} \mathrm{~N}_{\text {yellow crazy ant }}-\delta^{15} \mathrm{~N}_{(2)}-\Delta_{\mathrm{N}^{\prime \prime}}\right]+\left[\delta^{15} \mathrm{~N}_{(1)}\right.\right. \\
\left.+\Delta_{\mathrm{N}^{\prime}}-\delta^{15} \mathrm{~N}_{\text {yellow crazy ant }}\right] \\
\rho_{2}=1-\rho_{1}
\end{gathered}
$$

where $\delta^{15} \mathrm{~N}_{(1)}$ and $\delta^{15} \mathrm{~N}_{(2)}$ are the values for potential dietary resources of plants and spiders, respectively, and $\Delta_{\mathrm{N}}$ is the mean enrichment from plants to herbivores at each site and $\Delta_{\mathrm{N}}$, is the mean enrichment from herbivores to spiders at each site. We then calculated yellow crazy ant trophic position at each site as

$$
\mathrm{TP}_{\text {yellow crazy ant }}=\mathrm{TP}_{\text {spiders }}+1-\left(\mathrm{TP}_{\text {spiders }}-\mathrm{TP}_{\text {plants }}\right) \rho_{1}
$$

\section{Statistical analysis}

We tested for correlations between yellow crazy ant abundance and carbohydrate availability across sites in each location with Spearman rank tests between each measure of yellow crazy ant abundance and the calculated honeydew production over 24 hours, the number of tended hemipterans, the number of untended hemipterans, the number of fresh flowers, and the number of extrafloral nectaries. Where we found an association between a yellow crazy ant abundance measure and a measure of carbohydrate availability, we also tested for associations with our key habitat variables with Spearman rank tests. 
We tested the hypothesis that trophic position would increase as yellow crazy ant abundance decreased with Spearman rank tests between yellow crazy ant trophic position and each measure of yellow crazy ant abundance.

Although non-parametric tests tend to be more conservative than parametric tests, we opted for non-parametric tests to avoid the constraints of assumptions about error distributions with five sites (samples) per location. We used 1-tailed tests because we predicted the directions of the correlations.

For significant associations, we determined the best fit line (with the highest $\mathrm{R}^{2}$ ) with ANOVA and report the equation of the line where either the logarithmic or linear relationship described the fit with a p value of $<0.05$. We added 1 to the independent variable to test for logarithmic relationships.

\section{Results}

Yellow crazy ant relative abundance ranged among sites at both locations. Total yellow crazy ant abundance at the nine cat food and jam lure stations combined for each site ranged from 187-722 in Arnhem Land and 378-758 in New Caledonia (Table 1). We did not observe native ants on either lure type, in either location. We observed other non-native ants on 5 out of the 180 total lures, all in New Caledonia, and in all cases, yellow crazy ants far outnumbered them. Sites in New Caledonia tended to have fewer yellow crazy ant nests (4-14) than in Arnhem Land (11-68), most likely due to less leaf litter and sparser vegetation (Suppl. material 1: Table S2, Lach et al. 2020). In Arnhem Land, the number of yellow crazy ants on cat food lures positively correlated with the number of nests and card counts but not yellow crazy ants on jam lures. In New Caledonia, the number of yellow crazy ants on cat food lures positively correlated with the number on jam lures, but not with nests or card counts (Table 2).

In both locations, measures of yellow crazy ant abundance strongly positively correlated with carbohydrate availability. The number of yellow crazy ants on cat food and jam lures correlated with the number of plants with tended hemipterans in both locations (Table 2). In Arnhem Land, the relationships were logarithmic (cat food) or exponential (jam, Fig. 2A) (Table 3), whereas in New Caledonia they were linear (Table 3, Fig. 2B). In Arnhem Land, the number of yellow crazy ants on cat food, number of nests, and card counts all strongly positively correlated with honeydew production, the number of tended hemipterans, and the number of extrafloral nectaries (Table 2). The relationships between abundance on cat food lures-honeydew production (Fig. 2C) and abundance on cat food lures-tended hemipterans best fit logarithmic curves, whereas the nest-honeydew production, nest-tended hemipterans, card count-honeydew production, and card count-tended hemipteran relationships were linear or power curves (Table 3). In New Caledonia, the number of yellow crazy ants on jam lures positively correlated with honeydew production (Fig. 2D) and the number of tended hemipterans, with a trend toward a logarithmic relationship for both (Tables 2, 3). None of the plants in New Caledonia were observed to have extrafloral nectaries. We 
Table I. Summary of yellow crazy ant abundance and carbohydrate resources by site. All measures are the sum of values for a grid of nine $1 \mathrm{~m}$ diameter plots within each $20 \mathrm{~m} \times 20 \mathrm{~m}$ site, except nests (see text). $\mathrm{EFNs}=$ extrafloral nectaries.

\begin{tabular}{|c|c|c|c|c|c|c|c|c|c|c|c|}
\hline Site & $\begin{array}{c}\text { Sum cat } \\
\text { food } \\
\text { lures }\end{array}$ & $\begin{array}{c}\text { Sum jam } \\
\text { lures }\end{array}$ & $\begin{array}{c}\text { Total } \\
\text { on } \\
\text { lures }\end{array}$ & Nests & $\begin{array}{c}\text { Sum } \\
\text { card } \\
\text { counts }\end{array}$ & $\begin{array}{l}\text { Total number } \\
\text { of tended } \\
\text { native } \\
\text { hemipterans }\end{array}$ & $\begin{array}{c}\text { Total number } \\
\text { of tended } \\
\text { non-native } \\
\text { hemipterans }\end{array}$ & $\begin{array}{c}\text { Honeydew } \\
\text { mg/24h } \\
\text { from native } \\
\text { hemipterans }\end{array}$ & $\begin{array}{c}\text { Honeydew } \\
\text { mg/24h from } \\
\text { non-native } \\
\text { hemipterans }\end{array}$ & EFNs & $\begin{array}{c}\text { Fresh } \\
\text { flowers }\end{array}$ \\
\hline Arnhem Land 1 & 532 & 190 & 722 & 68 & 149 & 584 & 41 & 4275 & 23.3 & 3511 & 1 \\
\hline Arnhem Land 2 & 423 & 72 & 495 & 19 & 4 & 14 & 0 & 265 & 0 & 435 & 173 \\
\hline Arnhem Land 3 & 163 & 24 & 187 & 11 & 0 & 0 & 0 & 0 & 0 & 338 & 3 \\
\hline Arnhem Land 4 & 499 & 257 & 756 & 22 & 18 & 32 & 0 & 898 & 0 & 2462 & 28 \\
\hline Arnhem Land 5 & 438 & 28 & 466 & 41 & 34 & 20 & 0 & 686 & 0 & 441 & 5 \\
\hline New Caledonia 1 & 485 & 273 & 758 & 4 & 7 & 0 & 1453 & 0 & 708 & 0 & 10 \\
\hline New Caledonia 2 & 405 & 221 & 626 & 14 & 3 & 1 & 147 & 1.7 & 46.8 & 0 & 2 \\
\hline New Caledonia 3 & 314 & 64 & 378 & 9 & 5 & 0 & 0 & 0 & 0 & 0 & 57 \\
\hline New Caledonia 4 & 326 & 128 & 454 & 6 & 2 & 0 & 1 & 0 & 0.1 & 0 & 101 \\
\hline New Caledonia 5 & 210 & 70 & 280 & 9 & 1 & 0 & 29 & 0 & 17.3 & 0 & 10 \\
\hline
\end{tabular}

Table 2. Spearman rho correlation coefficients between measures of yellow crazy ant (YCA) abundance, carbohydrate availability, and mean trophic position in Arnhem Land, Australia, and New Caledonia. * indicates significance at $\mathrm{p}<0.05,{ }^{* *} \mathrm{p}<0.02, \mathrm{df}=5$ for all comparisons.

\begin{tabular}{|c|c|c|c|c|}
\hline & YCA on cat food & YCA on jam & YCA nests & YCA on cards \\
\hline \multicolumn{5}{|l|}{ Arnhem Land $(\mathrm{n}=5)$} \\
\hline \multicolumn{5}{|l|}{ yellow crazy ant abundance } \\
\hline on cat food & - & 0.800 & $0.900^{*}$ & $0.900^{*}$ \\
\hline on jam & - & - & 0.500 & 0.500 \\
\hline nests & - & - & - & $1.000^{* *}$ \\
\hline \multicolumn{5}{|l|}{ carbohydrate resource } \\
\hline honeydew production & $1.000^{* *}$ & 0.800 & $0.900^{*}$ & $0.900^{*}$ \\
\hline number of tended hemipterans & $1.000^{* *}$ & 0.800 & $0.900^{*}$ & $0.900^{*}$ \\
\hline number of plants with tended hemipterans & $0.872^{*}$ & $0.975^{* *}$ & 0.616 & 0.616 \\
\hline extrafloral nectaries & $1.000^{* *}$ & 0.800 & $0.900^{*}$ & $0.900^{*}$ \\
\hline number of flowers & -0.300 & 0.200 & -0.400 & -0.400 \\
\hline number of untended hemipterans & -0.205 & 0.051 & 0.435 & -0.103 \\
\hline trophic position & $-0.900^{*}$ & -0.500 & $-1.000^{* *}$ & $-1.000^{* *}$ \\
\hline \multicolumn{5}{|l|}{ New Caledonia $(\mathrm{n}=5)$} \\
\hline \multicolumn{5}{|l|}{ yellow crazy ant abundance } \\
\hline on cat food & - & $0.900^{*}$ & -0.359 & 0.700 \\
\hline on jam & - & - & -0.359 & 0.400 \\
\hline nests & - & - & - & -0.359 \\
\hline \multicolumn{5}{|l|}{ carbohydrate resource } \\
\hline honeydew production & 0.700 & $0.900^{*}$ & -0.205 & 0.300 \\
\hline total number of tended hemipterans & 0.700 & $0.900^{*}$ & -0.205 & 0.300 \\
\hline number of plants with tended hemipterans & $0.821^{*}$ & $0.975^{* *}$ & -0.289 & 0.359 \\
\hline number of flowers & -0.308 & -0.462 & -0.500 & -0.103 \\
\hline number of untended bugs & 0.000 & -0.400 & 0.103 & 0.300 \\
\hline trophic position & $-1.000^{* *}$ & $-0.900^{*}$ & 0.359 & -0.700 \\
\hline
\end{tabular}

did not observe yellow crazy ants imbibing floral nectar in either location and no measure of yellow crazy ant abundance correlated with fresh flower abundance (Table 2). No measure of yellow crazy ant abundance correlated with the number of untended hemipterans ( $\mathrm{p}>0.3$ in all cases).

In Arnhem Land $99.6 \%$ of honeydew came from native species, whereas in New Caledonia, only $0.2 \%$ of honeydew was produced by a native hemipteran (Table 1 ). In 
A Arnhem Land

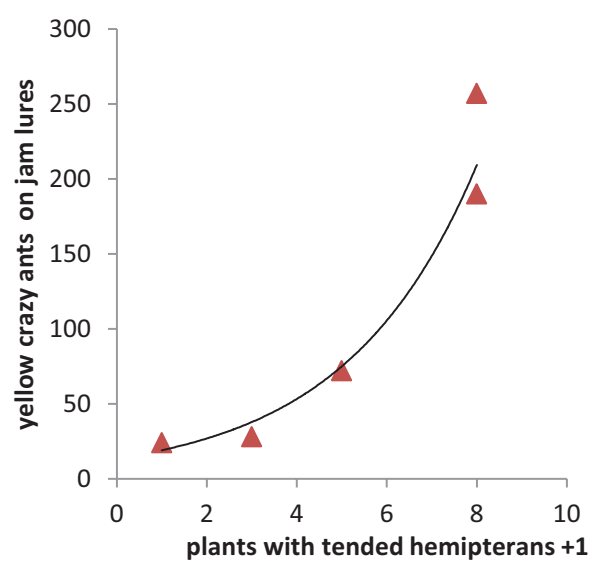

B New Caledonia

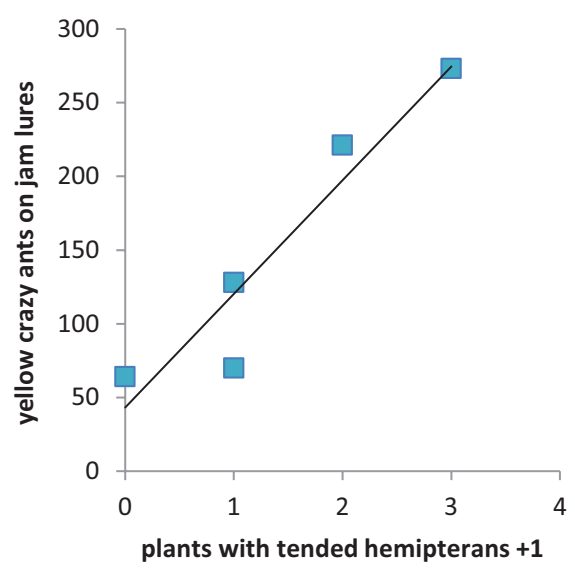

C Arnhem Land

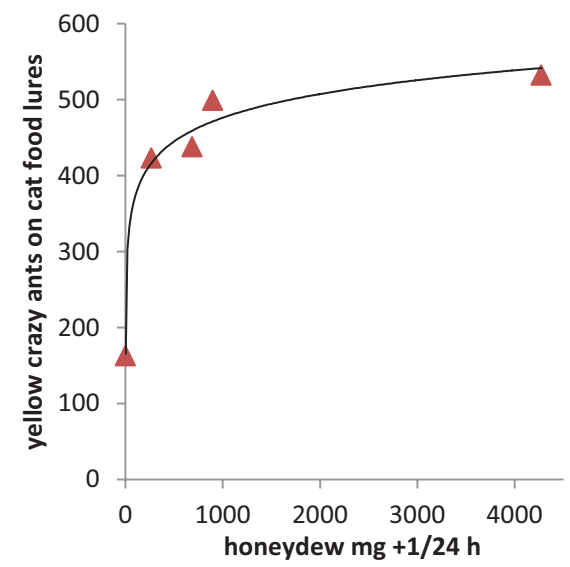

D New Caledonia

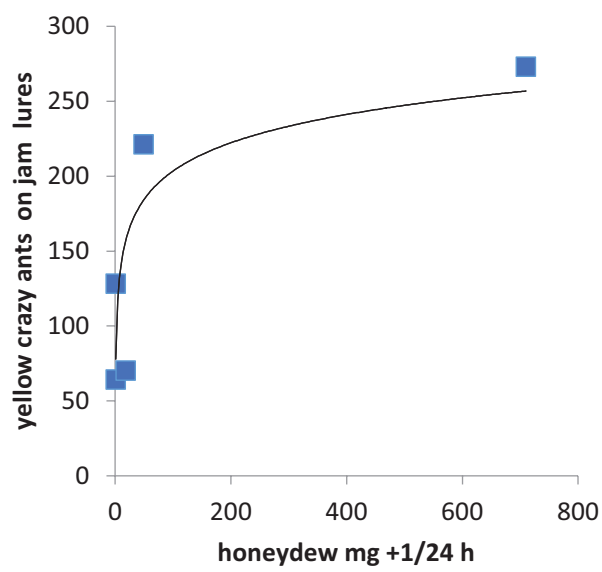

Figure 2. Correlations between carbohydrate resources and yellow crazy ant abundance: the number of plants with yellow crazy ant-tended hemipterans by yellow crazy ants on jam lures in A Arnhem Land and $\mathbf{B}$ New Caledonia and calculated honeydew production by yellow crazy ant abundance on $\mathbf{C}$ cat food lures in Arnhem Land, and D on jam lures in New Caledonia. Spearman rho correlations and equations for best fit lines are in Tables 2, 3. Note difference in y-axis scale between $\mathbf{C}$ and $\mathbf{A}, \mathbf{B}$, and $\mathbf{D}$.

Arnhem Land, only one of the 13 species of honeydew-producing hemipteran species was non-native, whereas in New Caledonia, three of the five identified species were non-native, and one was of unknown origin (Suppl. material 1: Tables S3, S4). More honeydew was available in Arnhem Land due to the presence of large-bodied producers (Membracidae and Cicadellidae) in most sites. The main contributors to honeydew production in Arnhem Land were the widely-distributed membracid, Sextius virescens 
Table 3. Best line fit for ant abundance variables that had significant correlations with carbohydrate measures or mean trophic position for each study location in Table 2 . For all analyses $\mathrm{df}=4$.

\begin{tabular}{|c|c|c|c|c|c|c|}
\hline & Relationship & $\mathbf{R}^{2}$ & $\operatorname{Adj} R^{2}$ & $\mathbf{F}$ & $\mathbf{p}$ & Equation of the line \\
\hline \multicolumn{7}{|l|}{ Arnhem Land $(n=5)$} \\
\hline \multicolumn{7}{|c|}{ Ant abundance $(\mathrm{y})$ by carbohydrate resource $(\mathrm{x})$} \\
\hline \multicolumn{7}{|c|}{ honeydew production $(\mathrm{mg} / 24 \mathrm{~h}+1)$} \\
\hline cat food lures & Logarithmic & 0.984 & 0.979 & 188 & 0.001 & $44.997 \ln (\mathrm{x})+165.50$ \\
\hline nests & Linear & 0.848 & 0.797 & 16.7 & 0.026 & $0.012 \times+17.389$ \\
\hline card counts & Linear & 0.981 & 0.975 & 155 & 0.001 & $0.035 \times-2.132$ \\
\hline \multicolumn{7}{|c|}{ number of tended hemipterans +1} \\
\hline cat food lures & Logarithmic & 0.899 & 0.808 & 12.7 & 0.038 & $57.03 \ln (\mathrm{x})+232.05$ \\
\hline nests & Power & 0.911 & 0.829 & 14.5 & 0.032 & $10.955 x^{0.2809}$ \\
\hline card counts & Linear & 0.963 & 0.951 & 78.1 & 0.003 & $0.223 x+9.991$ \\
\hline \multicolumn{7}{|c|}{ number of plants with tended hemipterans } \\
\hline cat food lures & Logarithmic & 0.915 & 0.887 & 32.4 & 0.011 & $160.42 \ln (x)+190.68$ \\
\hline jam lures & Exponential & 0.958 & 0.944 & 68.1 & 0.004 & $13.525 \mathrm{e}^{0.3424 x}$ \\
\hline \multicolumn{7}{|l|}{ extrafloral nectaries } \\
\hline cat food lures & Logarithmic & 0.531 & 0.375 & 3.40 & 0.16 & $96.22 \ln (\mathrm{x})-242.49$ \\
\hline nests & Linear & 0.469 & 0.293 & 2.65 & 0.20 & $0.0107 x+16.824$ \\
\hline card counts & Linear & 0.641 & 0.521 & 5.35 & 0.10 & $0.0338 x-7.6254$ \\
\hline \multicolumn{7}{|c|}{ trophic position (y) by ant activity (x) } \\
\hline cat food lures & Linear & 0.484 & 0.311 & 2.81 & 0.19 & $-0.0004 x+3.0169$ \\
\hline nests & Linear & 0.915 & 0.886 & 32.2 & 0.011 & $-0.0036 x+2.9637$ \\
\hline card counts & Linear & 0.930 & 0.907 & 40.1 & 0.008 & $-0.0014 x+2.9024$ \\
\hline \multicolumn{7}{|l|}{ New Caledonia $(\mathrm{n}=5)$} \\
\hline \multicolumn{7}{|c|}{ Ant abundance (y) by carbohydrate resource (x) } \\
\hline \multicolumn{7}{|c|}{ honeydew production $(\mathrm{mg} / 24 \mathrm{~h}+1)$} \\
\hline jam lures & Logarithmic & 0.660 & 0.547 & 5.8 & 0.095 & $27.26 \ln (\mathrm{x})+77.874$ \\
\hline \multicolumn{7}{|c|}{ total number of tended hemipterans +1} \\
\hline jam lures & Logarithmic & 0.701 & 0.602 & 7.05 & 0.077 & $25.74 \ln (x)+66.545$ \\
\hline \multicolumn{7}{|c|}{ number of plants with tended hemipterans } \\
\hline cat food lures & Linear & 0.600 & 0.467 & 4.5 & 0.124 & \\
\hline jam lures & Linear & 0.896 & 0.861 & 25.9 & 0.015 & $77.038 x+43.346$ \\
\hline \multicolumn{7}{|c|}{ trophic position (y) by ant activity $(\mathrm{x})$} \\
\hline jam lures & Logarithmic & 0.894 & 0.858 & 25.2 & 0.015 & $-0.278 \ln (\mathrm{x})+4.417$ \\
\hline cat food lures & Logarithmic & 0.861 & 0.814 & 18.5 & 0.023 & $-0.568 \ln (\mathrm{x})+6.371$ \\
\hline
\end{tabular}

(Fairmaire), and two cicadellids, Ipoella fidelis Evans and Katipo pallescens (Evans), all native species. Two other hemipteran species collected in Arnhem Land, a Steatococcus (Monophlebidae) and an Acizzia (Psyllidae) are new to science.

Several measures of yellow crazy ant abundance strongly negatively correlated with mean trophic position in both locations. Lower trophic positions indicate greater consumption of plant-derived resources, such as nectar and honeydew. In Arnhem Land, mean trophic position declined strongly with the number of yellow crazy ants on cat food lures (Fig. 3), number of nests, and card counts (Table 2). For nests and card counts, the correlation was linear (Table 3). In New Caledonia, trophic position declined logarithmically with both the number of yellow crazy ants on cat food lures and the number on jam lures (Tables 2, 3, Fig. 3).

We found only one environmental variable that correlated with all of the significantly correlated pairs of ant abundance and carbohydrate resource variables in one of our locations. The number of stems negatively correlated with the number of yellow crazy ants on cat food, honeydew production, number of tended hemipterans, and number of extrafloral nectaries in Arnhem Land (Suppl. material 1: Table S5). The 

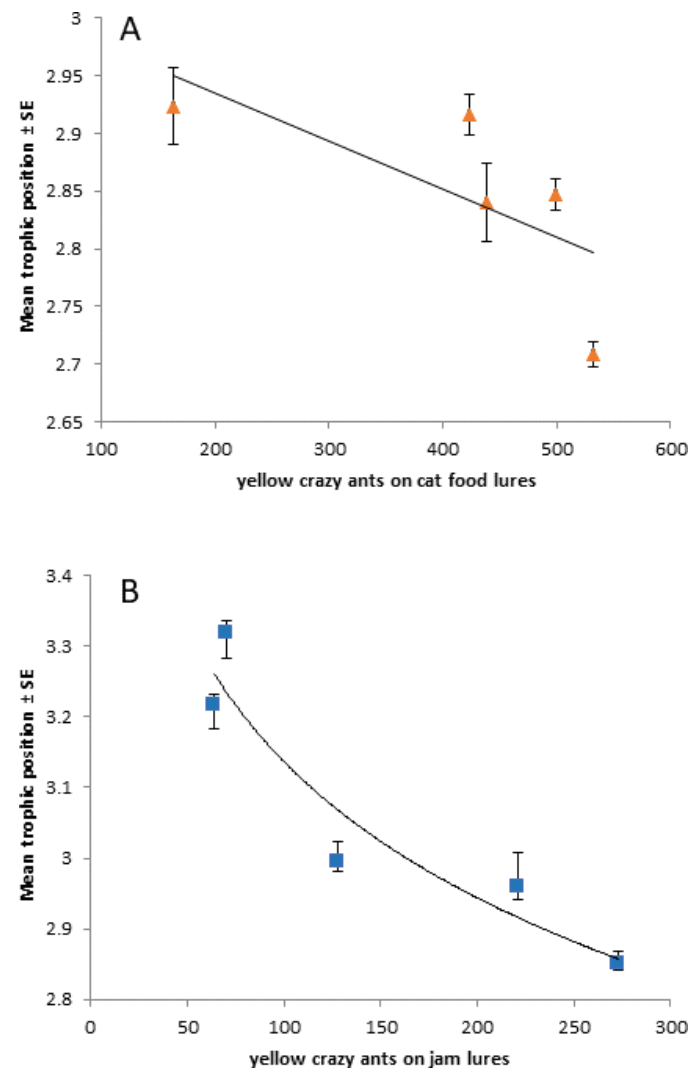

Figure 3. Best fit lines of the relationships between abundance of yellow crazy ants at $\mathbf{A}$ cat food lures in Arnhem Land and $\mathbf{B}$ jam lures in New Caledonia and mean trophic position. Note differences in scales. Spearman rho and significance values are in Table 2.

percentage of the ground covered with leaf litter positively correlated with both the number of yellow crazy ants on jam and the number of plants with tended hemipterans in Arnhem Land, but did not significantly correlate with any other measures of yellow crazy ant abundance or carbohydrate availability (Suppl. material 1: Table S5). Similarly, the percentage of the ground that was bare negatively correlated with the number of yellow crazy ants on jam and the number of plants with tended hemipterans in Arnhem Land (Suppl. material 1: Table S5). No environmental variables correlated with both ant abundance and carbohydrate resources in New Caledonia (Suppl. material 1: Table S6). The number of untended hemipterans correlated with several environmental variables in both locations (Suppl. material 1: Tables S5, S6).

\section{Discussion}

Our study reveals that both introduced and native honeydew-producers are associated with yellow crazy ant abundance. We found that yellow crazy ant abundance strongly 
positively correlated with carbohydrate availability across a series of sites in two distinct habitat types. We also found a strong negative correlation between relative trophic position and yellow crazy ant abundance, which is consistent with greater consumption of plant-based resources when ant abundance is high (Wittman et al. 2018). In our continental sites, 12 native hemipteran species contributed $99.6 \%$ of the honeydew and four native plant species contributed all of the extrafloral nectar utilized by the ant. In contrast, in our island sites, three species of non-native hemipterans contributed $99.8 \%$ of the carbohydrates utilized by yellow crazy ants. We did not observe yellow crazy ants consuming floral nectar in either country. This is the first study, of which we are aware, to quantify the relative representation of native and non-native sources of carbohydrates in both continental and island sites and their association with invasive ant abundance.

The ability to utilize and monopolize honeydew from a broad range of species may influence the ability of ants to invade new locations (invasiveness) (Holway et al. 2002; Lach 2003). The history of the yellow crazy ant on Christmas Island suggests that it required the arrival of a specific honeydew-producing scale insect to become invasive, despite the presence of several other honeydew-producing insects (Neumann et al. 2016). Among other invasive ant species, strong positive correlations between ant abundance and honeydew availability typically involve introduced honeydew-producers rather than native species (Helms 2013). Furthermore, in most other examples of invasive ants forming mutualisms with honeydew-producers, the latter are species of Sternorrhyncha (scale, mealybugs, aphids, whiteflies) (Helms 2013). This was also true in our study for New Caledonia, but differed largely in Arnhem Land. In Arnhem Land, the honeydew-producer assemblage was more diverse; it comprised a variety of taxa, including Sternorrhyncha, but the most prolific producers were three species of native Auchenorrhyncha. These three species are widely distributed across Australia (Fletcher 2009) and therefore, may facilitate other yellow crazy ant populations should efforts to control them fail. Our study, along with the only previous report of yellow crazy ants tending native honeydew-producing insects, the whitefly Neomaskellia bergeii in sugarcane fields in northern Queensland, Australia (Lach et al. 2019), suggests that lack of non-native honeydew producers does not impede yellow crazy ant invasion. This suggestion is also supported in Western Australia, where another invasive ant, Paratrechina longicornis (Latreille), was found in high abundances while tending native Sextius sp. treehoppers (M. Widmer pers. comm. 2020). Invasive ants, including yellow crazy ants, tend to be flexible and opportunistic in their use of resources, but identifying specific traits of honeydew producers that make them more likely to contribute to ant population increases may be a worthwhile area for future research.

We recognize that our correlative field data do not allow us to conclude that carbohydrate resources are driving yellow crazy ant abundance at our sites. However, the relationships between ants and honeydew-producing insects, as well as ants and extrafloral nectary plants, are widely regarded as mutualisms; it is likely that the yellow crazy ant is increasing the populations of these carbohydrate-providing partners as well as 
benefitting from them. The best fit curves of our significant correlations suggest a levelling off (logarithmic relationship) of yellow crazy ant abundance on lures as carbohydrate availability increases. Considering that significant associations for nests and card counts with carbohydrate availability always increased either linearly, exponentially, or following a power function, we believe that the levelling off we observed for lures may reflect a maximum number of yellow crazy ants that can feed simultaneously on a lure, rather than a true inability to utilize additional carbohydrate resources. Data from additional habitats in which yellow crazy ants displayed a range of densities would be helpful to confirm the trend. Furthermore, the negative correlation between trophic position and yellow crazy ant abundance provides further evidence that the ants were utilizing the additional carbohydrate resources and is consistent with other studies of invasive ants. High density populations of yellow crazy ants on Christmas Island incorporate a larger proportion of plant-based resources in their diet relative to low density populations (Wittman et al. 2018). Red imported fire ants and Argentine ants both have lower relative trophic positions in their introduced ranges than in their native ranges, reflecting the greater exploitation and assimilation of carbohydrate resources where they are invasive (Tillberg et al. 2007; Wilder et al. 2011b). Without certainty around the native range of the yellow crazy ant, we are not able to test whether it is utilizing plant-based carbohydrates more where it is invasive, but this would be a useful line of questioning for future research.

Yellow crazy ants did not include floral nectar in their diet in our sites, indicating that they do not utilize all plant-based carbohydrate resources. Many plants have evolved mechanisms to prevent ants from imbibing their floral nectar (e.g., toxic nectar, Junker et al. 2011), and it may be that yellow crazy ants have not been able to thwart such defenses if they existed on the flowers at our sites. The only previous reports of yellow crazy ants consuming floral nectar are on native Hawaiian plants (e.g., Lach 2005), which lack defenses against ants (Junker et al. 2011), and on pumpkin in India (Sinu et al. 2017), which, as a cultivated plant, is unlikely to have evolved mechanisms to prevent ant visits. In contrast, Argentine ants consume floral nectar in multiple ecological systems outside their native range (Blancafort and Gómez 2005; Lach 2013; LeVan et al. 2014). Considering the established relationship between invasive ants and carbohydrate resources, and the potential detrimental effects of nectar thievery on plants and pollinators (Blancafort and Gómez 2005; Lach 2013; LeVan et al. 2014), elucidating factors that influence invasive ants' abilities to utilize floral nectar may provide insights to both site invasibility and impact.

We think it unlikely that yellow crazy ant abundance and carbohydrate availability are non-interactive and are being driven by other site characteristics. We found no significant relationship between any measure of yellow crazy ant abundance and the abundance of untended herbivores, which allows us to rule out the possibility that yellow crazy ants and tended hemipterans were both independently responding to conditions conducive to insects generally. We recorded 15 environmental variables to describe substrate and vegetation structure and complexity, and only one of these at one location, number of stems in Arnhem Land, consistently correlated with both the 
ant abundance and carbohydrate availability measures. We might expect that yellow crazy ants, which have lower activity in open sunny areas (Hoffmann 2015), would increase with stem number, as would the number of hemipterans and extrafloral nectaries. However, yellow crazy ant abundance, honeydew production, number of tended hemipterans, and number of extrafloral nectaries all correlated negatively with the number of stems across sites in Arnhem Land. There is the possibility that stem density is reflecting some aspect of plant community composition not captured by our other environmental variables that independently affected hemipterans, extrafloral nectaries, and yellow crazy ants in some way. However, we know of no plant species or plant traits that would cause yellow crazy ants to become less abundant. The lower trophic position of yellow crazy ants with higher ant abundances underscores the low likelihood that the association between yellow crazy abundance and carbohydrate availability is confounded by some other site characteristic. We recognize that the influence of habitat characteristics may be complex or subtle and affect yellow crazy ant abundance in ways that were not detectable with our study design. However, we do not think that if such effects exist, that they can account for the strong associations we found between abundance and carbohydrate availability.

\section{Conclusions}

Our results demonstrate that the positive correlation between yellow crazy ant abundance and honeydew production is not contingent upon the provenance of the honeydew source. Predominantly native Auchenorrhyncha species correlated with yellow crazy ant abundance in our continental sites in Arnhem Land, Australia, whereas introduced Sternorrhyncha correlated with abundance in New Caledonia. Further work is required to determine if these patterns are consistent across island versus continental systems. The ability to achieve high densities is a hallmark of invasive ant species and is a key factor in their effects on native flora and fauna. Further investigations into ecological interactions, and mutualistic interactions in particular, will likely yield important insights into determinants of invasibility and the role of native species.

\section{Acknowledgements}

We thank Fabien Ravary for field assistance and Herve Jourdan for assistance with permits. We thank Mei Chen Leng for assisting with hemipteran weighing and Gregorz Skyrzpek at the West Australian Biogeochemistry Centre for conducting the stable isotope analyses. Monica Gruber, Sheldon Plentovich, Paul Krushelnycky, and an anonymous reviewer provided helpful comments on an earlier draft of the manuscript.

We collected material in New Caledonia under permits PC0992, PC0701, and PC0507 and imported material into Australia under permit IP12005806. 


\section{References}

Abbott KL (2005) Supercolonies of the invasive yellow crazy ant, Anoplolepis gracilipes, on an oceanic island: Forager activity patterns, density and biomass. Insectes Sociaux 52: 266273. https://doi.org/10.1007/s00040-005-0800-6

Antunes WC, Pompelli MF, Carretero DM, DaMatta FM (2008) Allometric models for nondestructive leaf area estimation in coffee (Coffea arabica and Coffea canephora). Annals of Applied Biology 153: 33-40. https://doi.org/10.1111/j.1744-7348.2008.00235.x

Australian Bureau of Meteorology (2020) Australian Bureau of Meteorology, Climate summary for Northern Territory. http://www.bom.gov.au/climate/current/annual/nt/archive/2012. summary.shtml\#summary [accessed 15 January 2020]

Berman M, Andersen AN, Hely C, Gaucherel C (2013) Overview of the distribution, habitat association and impact of exotic ants on native ant communities in New Caledonia. PLoS ONE 8(6): e67245. https://doi.org/10.1371/journal.pone.0067245

Blancafort X, Gómez C (2005) Consequences of the Argentine ant, Linepithema humile (Mayr), invasion on pollination of Euphorbia characias (L.) (Euphorbiaceae). Acta Oecologica 28: 49-55. https://doi.org/10.1016/j.actao.2005.02.004

Catford JA, Jansson R, Nilsson C (2009) Reducing redundancy in invasion ecology by integrating hypotheses into a single theoretical framework. Diversity and Distributions 15: 22-40. https://doi.org/10.1111/j.1472-4642.2008.00521.x

Cooling M, Hoffmann BD (2015) Here today, gone tomorrow: declines and local extinctions of invasive ant populations in the absence of intervention. Biological Invasions 17: 3351-3357. https://doi.org/10.1007/s10530-015-0963-7

Drescher J, Feldhaar H, Bluthgen N (2011) Interspecific aggression and resource monopolization of the invasive ant Anoplolepis gracilipes in Malaysian Borneo. Biotropica 43: 93-99. https://doi.org/10.1111/j.1744-7429.2010.00662.x

Fletcher MJ (2009 and updates) Identification keys and checklists for the leafhoppers, planthoppers and their relatives occurring in Australia and neighbouring areas (Hemiptera: Auchenorrhyncha). http://www1.dpi.nsw.gov.au/keys/leafhop/index.html [Accessed: 14 January 2020]

Gaigher R, Samways MJ, Henwood J, Jolliffe K (2011) Impact of a mutualism between an invasive ant and honeydew-producing insects on a functionally important tree on a tropical island. Biological Invasions 13: 1717-1721. https://doi.org/10.1007/s10530-010-9934-1

Gallardo B, Clavero M, Sánchez MI, Vilà M (2016) Global ecological impacts of invasive species in aquatic ecosystems. Global Change Biology 22: 151-163. https://doi.org/10.1111/gcb.13004

Gibson CWD, Dawkins HC, Brown VK, Jepsen M (1987) Spring grazing by sheep: effects on seasonal changes during early old field succession. Vegetatio 70: 33-43.

Godoy O (2019) Coexistence theory as a tool to understand biological invasions in species interaction networks: Implications for the study of novel ecosystems. Functional Ecology 33: 1190-1201. https://doi.org/10.1111/1365-2435.13343

Gonzalez AL, Kominoski JS, Danger M, Ishida S, Iwai N, Rubach A (2010) Can ecological stoichiometry help explain patterns of biological invasions? Oikos 119: 779-790. https:// doi.org/10.1111/j.1600-0706.2009.18549.x 
Grover CD, Kay AD, Monson JA, Marsh TC, Holway DA (2007) Linking nutrition and behavioural dominance: carbohydrate scarcity limits aggression and activity in Argentine ants. Proceedings of the Royal Society B-Biological Sciences 274: 2951-2957. https://doi. org/10.1098/rspb.2007.1065

Gruber MAM, Burne AR, Abbott KL, Pierce RJ, Lester PJ (2013) Population decline but increased distribution of an invasive ant genotype on a Pacific atoll. Biological Invasions 15: 599-612. https://doi.org/10.1007/s10530-012-0312-z

Guénard B, Weiser M, Gomez K, Narula N, Economo EP (2017) The Global Ant Biodiversity Informatics (GABI) database: a synthesis of ant species geographic distributions. Myrmecological News 24: 83-89.

Helms KR (2013) Mutualisms between ants (Hymenoptera: Formicidae) and honeydew-producing insects: Are they important in ant invasions? Myrmecological News 18: 61-71.

Helms KR, Vinson SB (2002) Widespread association of the invasive ant Solenopsis invicta with an invasive mealybug. Ecology 83: 2425-2438. https://doi.org/10.1890/00129658(2002)083[2425:WAOTIA]2.0.CO;2

Hill M, Holm K, Vel T, Shah NJ, Matyot P (2003) Impact of the introduced yellow crazy ant Anoplolepis gracilipes on Bird Island, Seychelles. Biodiversity and Conservation 12: 19691984. https://doi.org/10.1023/A:1024151630204

Hoffmann BD (2015) Integrating biology into invasive species management is a key principle for eradication success: the case of yellow crazy ant Anoplolepis gracilipes in northern Australia. Bulletin of Entomological Research 105: 141-151. https://doi.org/10.1017/ S0007485314000662

Hoffmann BD, Auina S, Stanley MC (2014) Targeted research to improve invasive species management: yellow crazy ant Anoplolepis gracilipes in Samoa. PLoS ONE 9(4): e95301. https://doi.org/10.1371/journal.pone.0095301

Hoffmann BD, Kay A (2009) Pisonia grandis monocultures limit the spread of an invasive ant-a case of carbohydrate quality? Biological Invasions 11: 1403-1410. https://doi. org/10.1007/s10530-008-9348-5

Hoffmann BD, Saul WC (2010) Yellow crazy ant (Anoplolepis gracilipes) invasions within undisturbed mainland Australian habitats: No support for biotic resistance hypothesis. Biological Invasions 12: 3093-3108. https://doi.org/10.1007/s10530-010-9701-3

Holway DA, Lach L, Suarez AV, Tsutsui ND, Case TJ (2002) The causes and consequences of ant invasions. Annual Review of Ecology and Systematics 33: 181-233. https://doi. org/10.1146/annurev.ecolsys.33.010802.150444

Janicki J, Narula N, Ziegler M, Guénard B, Economo EP (2016) Visualizing and interacting with large-volume biodiversity data using client-server web-mapping applications: The design and implementation of antmaps.org. Ecological Informatics 32: 185-193. https://doi. org/10.1016/j.ecoinf.2016.02.006

Junker RR, Daehler CC, Doetterl S, Keller A, Bluethgen N (2011) Hawaiian ant-flower networks: nectar-thieving ants prefer undefended native over introduced plants with floral defenses. Ecological Monographs 81: 295-311. https://doi.org/10.1890/10-1367.1

Kueffer C, Pyšek P, Richardson DM (2013) Integrative invasion science: Model systems, multisite studies, focused meta-analysis and invasion syndromes. New Phytologist 200: 615633. https://doi.org/10.1111/nph.12415 
Lach L (2003) Invasive Ants: Unwanted partners in ant-plant interactions? Annals of the Missouri Botanical Garden 90: 91-108. https://doi.org/10.2307/3298529

Lach L (2005) Interference and exploitation competition of three nectar-thieving invasive ant species. Insectes Sociaux 52: 257-262. https://doi.org/10.1007/s00040-005-0807-z

Lach L (2013) A comparison of floral resource exploitation by native and invasive Argentine ants. Arthropod-Plant Interactions 7: 177-190. https://doi.org/10.1007/s11829-012-9231-2

Lach L, Hoffmann BD (2011) Are invasive ants better plant-defense mutualists? A comparison of foliage patrolling and herbivory in sites with invasive yellow crazy ants and native weaver ants. Oikos 120: 9-16. https://doi.org/10.1111/j.1600-0706.2010.18803.x

Lach L, Hoffmann BD, Moir ML (2020) Environmental and stable isotope data to assess relationships between Anoplolepis gracilipes (yellow crazy ant) abundance and plant-based carbohydrate availability in New Caledonia and Arnhem Land, Australia [Data set]. James Cook University. https://doi.org/10.25903/31T1-9961

Lach L, Tillberg CV, Suarez AV (2010) Contrasting effects of an invasive ant on a native and an invasive plant. Biological Invasions 12: 3123-3133. https://doi.org/10.1007/s10530010-9703-1

Lach L, Volp TM, Greenwood TA, Rose A (2016) High invasive ant activity drives predation of a native butterfly larva. Biotropica 48: 146-149. https://doi.org/10.1111/btp.12284

Lach L, Volp TM, Wilder SM (2019) Previous diet affects the amount but not the type of bait consumed by an invasive ant. Pest Management Science 75: 2627-2633. https://doi. org/10.1002/ps.5365

Lester PJ, Tavite A (2004) Long-legged ants, Anoplolepis gracilipes (Hymenoptera: Formicidae), have invaded Tokelau, changing composition and dynamics of ant and invertebrate communities. Pacific Science 58: 391-401. https://doi.org/10.1353/psc.2004.0031

LeVan KE, Hung KLJ, McCann KR, Ludka JT, Holway DA (2014) Floral visitation by the Argentine ant reduces pollinator visitation and seed set in the coast barrel cactus, Ferocactus viridescens. Oecologia 174: 163-171. https://doi.org/10.1007/s00442-013-2739-z

Li W, Stevens MHH (2012) Fluctuating resource availability increases invasibility in microbial microcosms. Oikos 121: 435-441. https://doi.org/10.1111/j.1600-0706.2011.19762.x

Ludka J, Levan KE, Holway DA (2015) Infiltration of a facultative ant-plant mutualism by the introduced Argentine ant: effects on mutualist diversity and mutualism benefits. Ecological Entomology 40: 437-443. https://doi.org/10.1111/een.12206

Meteo France, New Caledonia Weather and Climate (2020) Meteo France, New Caledonia Weather and Climate. http://www.meteo.nc/nouvelle-caledonie/climat/fiches-climatologiques\# [accessed 11 January 2020]

Moir ML, Renton M, Hoffmann BD, Leng MC, Lach L (2018) Development and testing of a standardized method to estimate honeydew production. PLoS ONE 13(8): e0201845. https://doi.org/10.1371/journal.pone.0201845

Neumann G, O’Dowd DJ, Gullan PJ, Green PT (2016) Diversity, endemism and origins of scale insects on a tropical oceanic island: Implications for management of an invasive ant. Journal of Asia-Pacific Entomology 19: 159-166. https://doi.org/10.1016/j.aspen.2015.12.015

Northfield TD, Laurance SGW, Mayfield MM, Paini DR, Snyder WE, Stouffer DB, Wright JT, Lach L (2018) Native turncoats and indirect facilitation of species invasions. Proceed- 
ings of the Royal Society B-Biological Sciences 285: e20171936. https://doi.org/10.1098/ rspb.2017.1936

Novoa A, Richardson DM, Pyšek P, Meyerson LA, Bacher S, Canavan S, Catford JA, Čuda J, Essl F, Foxcroft LC, Genovesi P, Hirsch H, Hui C, Jackson MC, Kueffer C, Le Roux JJ, Measey J, Mohanty NP, Moodley D, Müller-Schärer H, Packer JG, Pergl J, Robinson TB, Saul W-C, Shackleton RT, Visser V, Weyl OLF, Yannelli FA, Wilson JRU (2020) Invasion syndromes: a systematic approach for predicting biological invasions and facilitating effective management. Biological Invasions 22: 1801-1820. https://doi.org/10.1007/s10530020-02220-w

O’Dowd DJ, Green PT, Lake PS (2003) Invasional 'meltdown' on an oceanic island. Ecology Letters 6: 812-817. https://doi.org/10.1046/j.1461-0248.2003.00512.x

Paini DR, Sheppard AW, Cook DC, De Barro PJ, Worner SP, Thomas MB (2016) Global threat to agriculture from invasive species. Proceedings of the National Academy of Sciences 113: e7575. https://doi.org/10.1073/pnas.1602205113

Perkins LB, Nowak RS (2013) Invasion syndromes: hypotheses on relationships among invasive species attributes and characteristics of invaded sites. Journal of Arid Land 5: 275-283. https://doi.org/10.1007/s40333-013-0161-3

Post DM (2002) Using stable isotopes to estimate trophic position: models, methods, and assumptions. Ecology 83: 703-718. https://doi.org/10.2307/3071875

Rowles AD, Silverman J (2009) Carbohydrate supply limits invasion of natural communities by Argentine ants. Oecologia 161: 161-171. https://doi.org/10.1007/s00442-009-1368-z

Savage AM, Johnson SD, Whitney KD, Rudgers JA (2011) Do invasive ants respond more strongly to carbohydrate availability than co-occurring non-invasive ants? A test along an active Anoplolepis gracilipes invasion front. Austral Ecology 36: 310-319. https://doi. org/10.1111/j.1442-9993.2010.02152.x

Savage AM, Rudgers JA (2013) Non-additive benefit or cost? Disentangling the indirect effects that occur when plants bearing extrafloral nectaries and honeydew-producing insects share exotic ant mutualists. Annals of Botany 111: 1295-1307. https://doi.org/10.1093/aob/mct082

Simberloff D, Von Holle B (1999) Positive interactions of nonindigenous species: invasional meltdown? Biological Invasions 1: 21-32. https://doi.org/10.1023/A:1010086329619

Sinu PA, Sibisha VC, Reshmi MVN, Reshmi KS, Jasna TV, Aswathi K, Megha PP (2017) Invasive ant (Anoplolepis gracilipes) disrupts pollination in pumpkin. Biological Invasions 19: 2599-2607. https://doi.org/10.1007/s10530-017-1470-9

Tillberg CV, Holway DA, LeBrun EG, Suarez AV (2007) Trophic ecology of invasive Argentine ants in their native and introduced ranges. Proceedings of the National Academy of Sciences of the United States of America 104: 20856-20861. https://doi.org/10.1073/ pnas.0706903105

Traveset A, Richardson DM (2014) Mutualistic Interactions and biological invasions. Annual Review of Ecology, Evolution, and Systematics 45: 89-113. https://doi.org/10.1146/annurev-ecolsys-120213-091857

Wetterer JK (2005) Worldwide distribution and potential spread of the long-legged ant, Anoplolepis gracilipes (Hymenoptera: Formicidae). Sociobiology 45: 77-97. 
Wilder SM, Holway DA, Suarez AV, Eubanks MD (2011a) Macronutrient content of plantbased food affects growth of a carnivorous arthropod. Ecology 92: 325-332. https://doi. org/10.1890/10-0623.1

Wilder SM, Holway DA, Suarez AV, LeBrun EG, Eubanks MD (2011b) Intercontinental differences in resource use reveal the importance of mutualisms in fire ant invasions. Proceedings of the National Academy of Sciences of the United States of America 108: 2063920644. https://doi.org/10.1073/pnas.1115263108

Wittman SE, O’Dowd DJ, Green PT (2018) Carbohydrate supply drives colony size, aggression, and impacts of an invasive ant. Ecosphere 9: 1-11. https://doi.org/10.1002/ecs2.2403

Young GR, Bells GA, Brown GR, Smith ESC (2001) The crazy ant Anoplolepis gracilipes (Smith) (Hymenoptera: Formicidae) in East Arnhem Land, Australia. Australian Entomologist 28: 97-104.

\section{Supplementary material I}

\section{Tables S1-S6}

Authors: Lori Lach, Benjamin D. Hoffmann, Melinda L. Moir

Data type: GPS points and additional data

Explanation note: GPS points, environmental data, honeydew production, correlation coefficients.

Copyright notice: This dataset is made available under the Open Database License (http://opendatacommons.org/licenses/odbl/1.0/). The Open Database License $(\mathrm{ODbL})$ is a license agreement intended to allow users to freely share, modify, and use this Dataset while maintaining this same freedom for others, provided that the original source and author(s) are credited.

Link: https://doi.org/10.3897/neobiota.63.57925.suppl1 